\title{
Normal Faulting Movement During the 2020 Mw 6.4 Yutian Earthquake: A Shallow Rupture in NW Tibet Revealed by Geodetic Measurements
}

Jiansheng Yu

Institute of Seismology China Earthquake Administration https://orcid.org/0000-0002-4483-8695

Dongzhen Wang

Institute of Seismology China Earthquake Administration

Bin Zhao (D zhaobin@cgps.ac.cn )

China Earthquake Administration https://orcid.org/0000-0002-0484-592X

Li Qi

Institute of Seismology China Earthquake Administration

Full paper

Keywords: The 2020 Yutian earthquake, Normal faulting, Bayesian approach, slip distribution $₫$ Coulomb stress changes, NW Tibetan Plateau

Posted Date: December 4th, 2020

DOl: https://doi.org/10.21203/rs.3.rs-120305/v1

License: (9) This work is licensed under a Creative Commons Attribution 4.0 International License.

Read Full License 


\section{Abstract}

The ENE striking Longmu Co fault and the North Altyn Tagh left-lateral slip fault have led to the complex regional structure in the northwestern Tibetan Plateau, resulting in a series of normal faulting and strike slip faulting earthquakes. Using both the ascending and descending Sentinel-1A/B radar images, we depict the coseismic deformation caused by the 2020 Yutian Mw 6.4 earthquake with a peak subsidence of $\sim 20 \mathrm{~cm}$. We determine the seismogenic fault geometry by applying the Bayesian approach with a Markov Chain Monte Carlo sampling method, which enables us to find the posterior probability density functions of the source model parameters. The estimation results reveal that the earthquake have dominantly by normal slip with moderate strike slip component. Based on the optimal fault geometry model, we extend the fault plane and invert for the finite fault model dislocation, which indicate that the slip is mainly concentrated at a shallow focal depth of 3-10 km with a maximum slip of $\sim 1.0 \mathrm{~m}$. Our preferred geodetic coseismic model exhibits no surface rupture, which may likely due to the shallow slip deficit in the uppermost crust. We calculate the combined loading effect of the Coulomb failure stress changes induced by the coseismic dislocations and postseismic viscoelastic relaxation of the $2008 \mathrm{Mw}$ 7.1 and $2014 \mathrm{Mw} 6.9$ Yutian events. Our study demonstrates that the two preceding major Yutian shocks were insufficient to trigger the 2020 Yutian earthquake, which we consider perhaps reflects the natural release of elastic strain accumulated mainly through localized tectonic movement. We attribute the 2020 Yutian event to the release of extensional stress in a stepover zone controlled by the Longmu Co and the North Altyn Tagh sinistral strike slip fault systems. The seismic risk in the southwest end of the North Altyn Tagh fault has been elevated by the Yutian earthquake sequences, which require future attention.

\section{Introduction}

Over the past two decades, a series of moderate-sized and strong earthquakes have occurred at the boundary surrounding area of the Bayan Har block in the central and northern Tibetan Plateau, which has become the most active block in the plateau, significantly increasing the seismicity around the block (Elliott et al. 2010; Lin et al. 2011; Ren et al. 2013; Wu et al. 2014). The Bayan Har block is bounded by several active strike-slip and reverse faults, including the left-lateral Ganzi-Yushu slip fault in the southern boundary, the Longmenshan thrust slip fault in the eastern boundary, and the East Kunlun fault in the northern boundary. Since the 1997 Mw 7.6 Manyi earthquake, several strong, highly destructive earthquakes with moment magnitudes greater than 6.5 have occurred at the boundaries of the Bayan Har block in succession, including the $2001 \mathrm{Mw} 7.8$ Kokoxili earthquake, 2008 Mw 7.1 Yutian and Mw 7.9 Wenchuan earthquake, 2010 Mw 6.9 Yushu earthquake, 2013 Mw 6.6 Lushan earthquake, and the 2014 Mw 6.9 Yutian earthquake (Ryder et al. 2011; Xu et al. 2013; Wu et al. 2014; Liu et al. 2015; Li et al. 2020). A series of recent seismic rupture events along the northern and eastern boundaries of the Bayan Har block indicates that the block has extruded eastward by about $7 \mathrm{~m}$. However, the extension movement of the west boundary of the block does not match well with the overall displacement caused by the eastward extrusion, which led to the continuous extension tectonics of the west boundary. It has been noted that the stress interactions within fault segments can play a key role in the seismicity of 
earthquake triggering and clustering (Oglesby 2005; Ryder et al. 2012; Jia et al. 2012; Wang et al. 2014). Studies have argued that these strong earthquake sequences can be attributed to the response of the Indian plate to the northward subduction beneath the Eurasian continent, which makes the internal materials of the Tibetan Plateau move eastward, resulting in an increased seismic activities around the Bayan Har block (Xu et al. 2013).

On 26 June 2020 (local time), a moderate Ms 6.4 earthquake with a focal depth of $10 \mathrm{~km}$ struck the northwest Tibetan Plateau in Yutian County, Hotan Prefecture, Xinjiang Uygur Autonomous Region, China, according to the China Earthquake Networks Center (CENC). The epicenter (82.33E, 35.73N) was located at the junction of Yutian County and Gaize County in the northwestern Tibetan Plateau, with an average altitude of $\sim 5500 \mathrm{~m}$. There are two snow and glacier-covered high-altitude mountains in the east and west sides of the epicenter, with the highest elevation point on the west side lying at Qiongmuztag (6989 $\mathrm{m}$ ) in the middle section of the Kunlun Shan terrain. Meanwhile, the Heishibei Lake lays several tens of kilometers southeast of the 2020 Yutian epicenter, which is considered to be surrounded by the youngest volcanic activities in the plateau since the late Quaternary (Wang et al. 2005). The determination of the epicentral positions varies among different research institutions (Table 1), with the locations roughly distributed in a range of $\mathrm{N} 35.58^{\circ}-35.70^{\circ}$, E82.36 $36^{\circ}-82.46^{\circ}$. As of August 21,2020 , a total of 468 aftershocks were recorded by the CENC, including 250 aftershocks with local magnitude (ML) $\geq 2$ (Fig. 1a). These aftershock sequences displayed a SSW trend, which is roughly consistent with one of the nodal planes of the mainshock. Meanwhile, ten $M>4$ aftershocks were located according to the United States Geological Survey (USGS), which also exhibited SSW trending distribution (Fig. 1b). The focal mechanism solutions provided by various institutions show that the 2020 Yutian earthquake was dominated by a normal faulting rupture with a minor strike slip component, indicating that there is a significant NW-SE trending local crustal extensional structure in the epicenter area. 
Table 1

Focal parameters of the 2020 Yutian earthquake given by different organizations.

\begin{tabular}{|c|c|c|c|c|c|c|c|}
\hline Source & $\begin{array}{l}\text { Strike } \\
\left({ }^{\circ}\right)\end{array}$ & $\begin{array}{l}\text { Dip } \\
\left({ }^{\circ}\right)\end{array}$ & $\begin{array}{l}\text { Rake } \\
\left(^{\circ}\right)\end{array}$ & $\begin{array}{l}\text { Magnitude } \\
(\mathrm{Mw})\end{array}$ & Depth (km) & $\begin{array}{l}\text { Longitude } \\
\left({ }^{\circ}\right)\end{array}$ & $\begin{array}{l}\text { Latitude } \\
\left(^{\circ}\right)\end{array}$ \\
\hline \multirow[t]{2}{*}{ USGS } & 227 & 50 & -74 & \multirow[t]{2}{*}{6.3} & \multirow[t]{2}{*}{10} & \multirow[t]{2}{*}{82.379} & \multirow[t]{2}{*}{35.596} \\
\hline & 24 & 42 & -108 & & & & \\
\hline \multirow[t]{2}{*}{ GCMT } & 213 & 52 & -66 & \multirow[t]{2}{*}{6.3} & \multirow[t]{2}{*}{13} & \multirow[t]{2}{*}{82.36} & \multirow[t]{2}{*}{35.70} \\
\hline & 357 & 44 & -117 & & & & \\
\hline \multirow[t]{2}{*}{ GEOFON } & 196 & 48 & -92 & \multirow[t]{2}{*}{6.3} & \multirow[t]{2}{*}{10} & \multirow[t]{2}{*}{82.43} & \multirow[t]{2}{*}{35.58} \\
\hline & 19 & 41 & -87 & & & & \\
\hline \multirow[t]{2}{*}{ IPGP } & 191 & 56 & -97 & \multirow[t]{2}{*}{6.3} & \multirow[t]{2}{*}{10} & \multirow[t]{2}{*}{82.452} & \multirow[t]{2}{*}{35.628} \\
\hline & 23 & 35 & -80 & & & & \\
\hline
\end{tabular}

The 2020 Ms 6.4 Yutian earthquake was the fourth moderate to major event of the recent Yutian Mw $>6$ earthquake sequences following the $2008 \mathrm{Mw} 7.1$ (Shan et al. 2011; Xu et al. 2013), $2012 \mathrm{Mw} 6.2$ (Bie et al. 2014a ) and $2014 \mathrm{Mw} 6.9$ earthquakes (Wu et al. 2014; Li et al. 2020). These events all occurred in the intersection area of the southwest segment of the North Altyn Tagh fault, Longmu Co fault and the Gozha Co fault, which is interpreted as part of the boundary of the West Kunlun and Bayan Har blocks (Zhang et al. 2014; Wu et al. 2014). The 2000-km-long sinistral strike-slip Altyn Tagh fault system defines the northwestern edge of the Tibetan Plateau (Xu et al. 2013; Li et al. 2015), which experienced strong tectonic activity in the Quaternary that accommodates a significant portion of India-Eurasia convergence (Tapponnier et al. 2001; Taylor and Yin, 2009). The northwest tail of the North Altyn Tagh fault system and its adjacent local tectonic background are extremely complicated, where develop strike-slip and normal faulting structures. Previous studies have shown that the focal mechanism solutions of the 2008 Mw 7.1 and $2014 \mathrm{Mw} 6.9$ Yutian events had normal fault and strike slip fault mechanisms, respectively (Xu et al. 2013; Li et al. 2020). The epicenter of the 2020 Yutian earthquake is located in the gap between the $2008 \mathrm{Mw} 7.1$ and $2014 \mathrm{Mw} 6.9$ Yutian events, less than $100 \mathrm{~km}$ away from the two preceding Mw $\geq$ 6.9 earthquakes. Several moderate-sized and strong earthquakes have successively occurred in this narrow spatial region, and the focal mechanism solutions demonstrate different tectonic backgrounds, which are worthy of further study and comprehensive analysis (Fig. 1).

In fact, the determination of the source parameters and coseismic slip distribution of the 2020 Ms 6.4 Yutian event is crucial to enhance our understanding of the seismogenic fault and the dynamic mechanism of the local regional tectonic evolution, and will contribute to elevate the potentially seismic hazard in the triple junction area of the North Altyn Tagh, Karakax, and Longmu Co fault systems. In this 
paper, we present the coseismic deformation field derived from the ascending and descending Interferometric Synthetic Aperture Radar (InSAR) interferometry images from Sentinel-1 satellites. Following this, we determine the seismogenic fault geometry using a Bayesian approach with a Markov Chain Monte Carlo method (MCMC). Subsequently, we invert for the detailed coseismic slip distribution of this seismic event. Furthermore, the stress disturbance and seismic hazard evaluation are also considered. Finally, the tectonic background of a series of the clustered Yutian earthquake sequences in the northwestern Tibetan Plateau is discussed.

\section{Insar Observations And Coseismic Deformation}

InSAR processing has proven to have the capacity to acquire continuous coseismic deformation field in remote and severe environments where lack of GPS observations, especially in terms of moderate-sized earthquakes in the Tibetan Plateau (Elliott et al. 2010; Bie et al. 2014a). Numerous studies on small and medium seismic events show that the source parameters and slip distribution determined by InSAR observation are superior to those constrained by traditional seismology methods in the Tibetan Plateau where seismic stations are insufficient (Elliott et al. 2010; Ryder et al. 2011; Xu et al. 2016; Chen et al. 2019). The current InSAR measurement can provide far higher resolution spatial constraints on the fault slip patterns of earthquakes occurring in a relatively remote boarder region under severe natural conditions and with a sparse population.

For the 2020 Yutian earthquake, we measured the coseismic deformation field from both the ascending (T158A) and descending (T165D) Sentinel-1A/B radar images operated by the European Space Agency with a revisiting phase of 12 days each (Table 2). To minimize the influence of the postseismic deformation and to reduce the impact from the digital elevation model (DEM) errors, we selected the shortest temporal (12 days) and spatial baselines $(<100 \mathrm{~m})$ for coseismic interference mapping. The Sentinel-1 interferograms were processed using the updated version of the GMTSAR software for multilooking by 8 looks in range and 2 looks in azimuth to improve the efficiency of the calculations and to reduce the data points noise (Sandwell et al. 2011). Meanwhile, to eliminate the topographic phase from the interferograms, we used the high resolution Shuttle Radar Topography Mission DEM and the precise orbital determination (Farr et al. 2007). Then, we obtained the unwrapped phase in the radar coordinates using the SNAPHU program after the adaptive filtering method was employed to reduce the phase noise (Chen and Zebker, 2000). Finally, we geocoded the unwrapped interferograms by transforming them from the range/azimuth coordinate system to the geographic coordinate system and converted them to line of sight (LOS) displacement applying the C-band wavelength of $\sim 5.6 \mathrm{~cm}$ (Fig. 2b, e). To eliminate the influence of atmospheric delay on the interferometric images, we employed the Generic Atmospheric Correction Online Service (GACOS) of InSAR developed by Newcastle University to correct the interference fringes, which generates high-resolution tropospheric delay maps for InSAR atmospheric correction (Yu, et al. 2018). Finally, the corrected coseismic deformation displacements were obtained (Fig. 2c, f). Here, we found that both the ascending and descending interferograms exhibited clearer coseismic signals than the originals after the GACOS online correction, especially in terms of the far-field. Figure 2 shows 
that the coseismic deformation of the InSAR measurements, including the original and corrected LOS displacement.

Table 2

Sentinel-1A/B image data used in this study.

\begin{tabular}{|c|c|c|c|c|c|c|}
\hline Track & Master & Slave & Bperp (m) & $\begin{array}{l}\Delta \mathrm{T} \\
\text { (days }\end{array}$ & $\operatorname{lnc}\left({ }^{\circ}\right)$ & Azi ( $\left(^{\circ}\right)$ \\
\hline T158A & $2020 / 06 / 22$ & $2020 / 07 / 04$ & 85 & 12 & $40.9-44.5$ & -9.8 \\
\hline T165D & 2020/06/17 & $2020 / 06 / 29$ & 87 & 12 & $34.6-39.5$ & -169.7 \\
\hline \multicolumn{7}{|c|}{ A and $\mathbf{D}$ in the Track represent the ascending and descending orbits, respectively. Bperp = } \\
\hline
\end{tabular}

We can clearly observe two main deformation lobes in the epicentral area with a maximum uplift and subsidence coseismic displacement of approximately $8 \mathrm{~cm}$ in the east and of $20 \mathrm{~cm}$ in the west, respectively. Most of the coseismic deformation is located in the western part with a high deformation gradient, indicating that the seismogenic fault plane is inclined to the west. The coseismic deformation is mainly distributed in a relatively flat area $\left(480 \mathrm{~km}^{2}\right)$ between the two high mountains where the altitude is over $6000 \mathrm{~m}$. Due to the severe decorrelation of InSAR interferometry in the snow and ice as well as lake and river covered areas, there were no available LOS results in these areas after unwrapping. While we can observe a distinct continuous fringe in the epicenter area, it seems that no clear surface rupture traces can be observed in both the ascending and descending interferometric maps. Furthermore, the InSAR coseismic deformation field indicates that the seismogenic fault with a strike lies in an approximately $\mathrm{N}-\mathrm{S}$ direction, which is consistent with one of the nodal plane parameters of the focal mechanisms.

\section{Fault Geometry And Coseismic Slip Model}

Based on the focal mechanism solutions and the InSAR coseismic deformation filed, we have the preliminary understanding that the 2020 Yutian earthquake was a normal faulting event that dipped to the west direction. The study of the geometry and location of normal faulting is of great significance to understanding the continental crustal extension and the mechanisms of faulting activity in the northwestern Tibetan Plateau (Elliott et al. 2010; Shan et al. 2011; Ryder et al. 2012; Wang et al. 2014; Bie et a. 2014a,b; Xu et al. 2016). Considering the computational efficiency and inversion simplicity, we adopted an adaptive quadtree downsampling method with an appropriate deformation gradient threshold to resample the original InSAR data containing points of an order of millions to the appropriate number and spatial resolution (Jónsson et al. 2002). Previous studies have suggested that the average incident 
angle of localized areas may have a great impact on the inversion results (Zhang et. al., 2011). Therefore, we calculated the unit vectors along LOS displacement at each downsampled point using the incidence and azimuth angles of different pixels according to the DEM and satellite orbit parameters. Finally, we obtained a total number of 643 points after downsampling from both the ascending and descending InSAR observations, attaining a higher density of sample points in the near-field of the seismogenic fault area and relatively sparse points in the far-field. We used a two-step procedure to construct the rupture model of the 2020 Yutian earthquake. In the first step, we adopted a Bayesian method to constrain the geometric parameters of seismogenic fault. Then, we extended the initial fault plane and inverted for the slip distribution of the seismic event using rectangular dislocation in a homogeneous elastic half-space (Okada 1985).

\subsection{Optimal Fault Geometry Parameters}

To obtain the optimal fault geometric parameters from the dense InSAR observations, we utilized a Bayesian approach to retrieve the optimal source parameters and related uncertainties through an MCMC method with an automatic step size selection, which allowed for rapid characterization of the posterior probability density functions (PDFs) of the model parameters (Bagnardi and Hooper 2018; Yu et al. 2020). Compared to the traditional optimal inversion algorithm, we can not only retrieve the optimal value of geometric parameters, but also obtain the error range of each parameter and the marginal PDFs using the Bayesian estimation method (Fukuda et al. 2010).

It is noted that the Bayesian estimation approach can distinguish two conjugate focal mechanism planes derived from seismic wave inversion. Hence, we did not impose any geometric constraints on the strike $\left(0^{\circ} \sim 360^{\circ}\right)$, dip $\left(-90^{\circ} \sim 90^{\circ}\right)$, and slip direction of the initial seismogenic fault, which meant all possible fault orientations and kinematic processes could be explored (Table 3). The inversion was carried out using a kinematic forward model for a rectangular dislocation source with nine fault model parameters, where the coseismic deformation can be well explained by a fault plane with a length of $12-13 \mathrm{~km}$ and a width of $6-8 \mathrm{~km}$. We observed the correlations among the nine source parameters of fault length, width, depth, strike, dip, horizontal position, strike-slip and dip-slip components. Figure 3 shows the marginal posterior PDFs of the fault geometric parameters and source model uncertainty after $1 \times 10^{6}$ iterations with a burn-in period discarding $5 \times 10^{4}$ samples. The optimal source model indicated that the seismogenic fault has a southwest dipping of $\sim 65^{\circ}$ and a SSW strike of $186^{\circ}$ (almost N-S trending), which is largely consistent with the results of the focal mechanism solutions. Our Bayesian estimation results reveal that within the $95 \%$ confidence interval, the earthquake was dominated by a normal-slip motion of $0.7-0.9 \mathrm{~m}$ with a strike slip component of $0.2-0.5 \mathrm{~m}$. 
Table 3

Prior information and inversion results of fault parameters for 2020 Yutian Mw 6.4 earthquake derived from Bayesian estimation.

\begin{tabular}{|c|c|c|c|c|c|c|c|c|c|}
\hline & $\begin{array}{l}\text { Length } \\
(\mathrm{km})\end{array}$ & $\begin{array}{l}\text { Width } \\
(\mathrm{km})\end{array}$ & $\begin{array}{l}\text { Depth } \\
\text { (km) }\end{array}$ & $\begin{array}{l}\text { Dip } \\
\left(^{\circ}\right)\end{array}$ & $\begin{array}{l}\text { Strike } \\
\left({ }^{\circ}\right)\end{array}$ & $\begin{array}{l}\text { X-center } \\
(\mathrm{km})\end{array}$ & $\begin{array}{l}\text { Y-center } \\
(\mathrm{km})\end{array}$ & $\begin{array}{l}\text { SS } \\
\text { (m) }\end{array}$ & $\begin{array}{l}\text { DS } \\
(\mathrm{m})\end{array}$ \\
\hline Lower & 5 & 1 & 0.1 & -90 & 0 & -5 & -5 & -1 & -1.5 \\
\hline Upper & 30 & 20 & 15 & 90 & 360 & 5 & 5 & 1 & 1.5 \\
\hline Optimal & 12.33 & 7.43 & 3.18 & 65 & 185.89 & 3.30 & 1.38 & 0.39 & -0.78 \\
\hline $2.5 \%$ & 12.02 & 6.78 & 3.07 & 63 & 185.39 & 3.24 & 1.04 & 0.21 & -0.84 \\
\hline $97.5 \%$ & 12.59 & 8.20 & 3.27 & 67 & 186.40 & 3.35 & 1.59 & 0.49 & -0.73 \\
\hline \multicolumn{10}{|c|}{$\begin{array}{l}\text { SS and DS represent strike-slip and dip-slip components, respectively. Note that the right-lateral SS is } \\
\text { positive while left-lateral SS is negative. DS is positive for thrust faulting and negative for normal } \\
\text { faulting. } X \text { and } Y \text { center means the coordinates of the midpoint of the upper edge related to the } \\
\text { reference point }\left(35.61^{\circ} \mathrm{N}, 82.42^{\circ} \mathrm{E}\right) \text { in the local coordinates system. }\end{array}$} \\
\hline
\end{tabular}

\subsection{Finite fault slip model}

Determining the distribution of coseismic slip is helpful to reveal numerous properties of seismic events, including the fault geometry, stress changes, friction properties, and potential seismic hazards (Shan et al. 2011; Amey et al. 2018; Zhao et al. 2018). According to the optimal fault geometry parameters obtained from the above Bayesian estimation, we further extend the fault plane to $30 \mathrm{~km}$ and $20 \mathrm{~km}$ along the strike and downdip directions, respectively. Finally, our constructed fault plane is discretized into $1 \mathrm{~km} \times 1 \mathrm{~km}$ rectangular subfaults (slip patches). Based on the rectangular dislocation in an elastic half-space homogeneous dislocation model with a Poisson's ratio of 0.25 (Okada 1985), we invert for the coseismic slip distribution of the 2020 Yutian earthquake (Fig. 4a). The preferred dip angle is determined to be $60^{\circ}$ via the trade-off curve of a grid search between the root-mean-square and fault dip with a wide dip ranging from $20^{\circ}$ to $90^{\circ}$ (Fig. $4 \mathrm{~d}$ ). The reasonable smoothing factor is generally achieved through the trade-off curve of the roughness and LOS data fitting residuals, which is set to 0.26 (Fig. 4e). The predicted LOS deformation calculated from the favored model is in good consistency with the observed LOS deformation fields (Fig. 4b, c). Meanwhile, we have plotted profiles of the ascending (AB) and descending (CD) InSAR deformation fields approximately perpendicular to the seismogenic fault, exhibiting the relationship between the geomorphology and surface displacements (Fig. 4f, g). The detailed spatial distribution of the coseismic slip on the optimal seismological fault plane indicates that the earthquake is dominated by a normal fault slip with moderate dextral lateral strike slip. Our coseismic model demonstrates that the maximum dip slip motion and strike slip movement reaches up to $0.95 \mathrm{~m}$ and $0.42 \mathrm{~m}$, respectively. The total slip is mainly concentrated at a depth of 3-10 km, with a peak slip of $\sim 1.0 \mathrm{~m}$. The resolved distributed coseismic slip on the fault patches indicates that the rupture did not reach the earth surface, which is consistent with the coseismic deformation field observed by InSAR. Assuming a standard rigidity of $32 \mathrm{GPa}$ for the shear modulus, we estimate the geodetic moment release 
of $4.28 \times 10^{18} \mathrm{Nm}$ using the aforementioned optimal model parameters, and this corresponded to an event of Mw 6.4, which is slightly larger than that in the focal mechanism solutions (Mw 6.3) determined by the seismological methods.

\section{Discussion}

\subsection{Shallow slip deficit}

According to the analysis of the focal mechanism solutions widely distributed in the Tibetan Plateau, the continuous seismic activity of normal faulting in the plateau reflects the existence of a local extensional stress filed in the upper crust. A swarm of small-to-moderate (Mw 6-7) normal faulting earthquakes have successively occurred in the Tibetan Plateau over the past decades, including the Zhongba (2004, Mw 6.2; 2005, Mw 6.3; 2008, Mw 6.7 and Mw 6.0), Damxung (1992, Mw 5.9; 2008, Mw 6.3), Gaize (2008 Mw 6.4 and Mw 5.9), and Yutian (2008, Mw 7.1; 2012, Mw 6.2; 2020, Mw 6.4) earthquake sequences (Elliott et al. 2010; Ryder et al. 2010, 2012; Bie et al. 2014b; He et al. 2020). The 2008 Damxung Mw 6.3 earthquake that occurred in the central Tibet indicates that the seismogenic fault was a normal faulting with an nearly N-S strike and a dip to the west (Bie et al. 2014a; Xu et al. 2016), which was very similar to the slip rupture of the 2020 Yutian earthquake. Through the combined investigation of the coseismic slip and the afterslip distribution of the 2008 Damxung earthquake, previous studies have suggested that the occurrence of the afterslip has migrated to a depth of $0-5 \mathrm{~km}$ in the upper layer of the elastic crust. Meanwhile, the total afterslip moment release was still small compared with the seismic moment inferred from the coseismic slip, indicating that the coseismic slip may have had a slip deficit in the shallow area of the causative fault.

The resolved slip on the fault patches near the surface of the 2020 Yutian event indicates no ground ruptures, which probably means the shallow slip deficit in the uppermost crust. Assuming a constant shear modulus and adopting the slip rate deficit on the fault plane, we calculated the seismic moment accumulation rate at each rectangular fault patch. Figure 5 shows the average seismic potency per unit length of rupture for the $2020 \mathrm{Mw} 6.4$ Yutian earthquake (this study) and that of preceding earthquakes acquired by using the InSAR observations (Fialko et al. 2005; Bie et al. 2014b; Chen et al. 2019). The maximum release of seismic moment occurs in the middle of the brittle layer at a depth of 4-9 km and gradually decreases toward the earth surface. The 2020 Yutian earthquake may be representative of a shallow slip deficit event, where the coseismic slip in the uppermost crust is systematically less than that at seismogenic depths. According to the historical seismicity in the vicinity of the Yutian region, the distribution of earthquake deformation is dispersed. The undefined seismogenic fault in the 2020 Yutian event maybe indicate a relatively young normal fault under developing, where its shallow part of the brittle crust is mainly distributed the inelastic deformation that can limit the coseismic slip at the rupture front (Fialko et al. 2005; Kaneko and Fialko et al. 2011).

\subsection{The Coulomb stress interaction and seismic risk}


Numerous studies have discussed the Coulomb failure stress (CFS) changes to explain the potential triggering relationship, which is of great significance to earthquake risk assessment (Jia et al. 2012; Li et al. 2015; Wang et al. 2016; Yu et al. 2020). The interaction between two or more strong seismic events can trigger more earthquakes in the surrounding area. When the change in CFS increases, more aftershocks occur in the periphery, and vice versa. Based on the distribution of coseismic dislocations, it is possible to calculate whether the stress had transferred onto the surrounding faults in view of identifying the regions of the fault systems that were brought closer to failure. To explore the influence of both the 2008 and the 2014 Yutian earthquakes on the 2020 Mw 6.4 Yutian event, we chose the nonplanar finite fault planes from the two earlier earthquakes, which constrained by using geodetic observation data (Elliott et al. 2011, Li et al. 2020). The two preceding Yutian coseismic slip models we used to calculate the CFS were different from that estimated directly by empirical relationship in previous research, which roughly estimate the rupture length, width and uniform slip from the seismic moment release (Wu et al. 2014; Bie et al. 2014b; Wang et al. 2016). While the stress variations can be quickly deduced by using the empirical formula and the uniform dislocation model, this results involves certain limitations since its spatial distribution is somewhat different from that of subsequent aftershocks. Wang et al. (2016) has compared the coseismic CFS changes calculated with the uniform dislocation and nonuniform dislocation models in relation to the 2008 Yutian seismic event, and found that the CFS changes calculated adopting the non-uniform dislocation model could better explain the aftershock activities.

We employed the PSGRN/PSCMP software released by Wang et al. (2006) to probe the stress-triggering effects considering the coseismic static stress changes and postseismic viscoelastic stress relaxation. Here we constructed a stratified spherical postseismic relaxation model consisting of an elastic upper crust with reference to the Crust 2.0 model (Bassin et al. 2000). The viscosity coefficients (Table 4) of the lower crust and upper mantle in the Yutian area were referred to the previous studies (Ryder et al. 2011; Li et al. 2015; Wang et al. 2016). Taking the seismological fault of the 2014 and 2020 Yutian earthquakes as the receiver faults, we calculated the coseismic and postseismic CFS changes at a focal depth of $7 \mathrm{~km}$ (maximum slip), with an effective friction coefficient of 0.4. The Coulomb stress calculation along the fault rupture direction indicated that the position of the 2014 mainshock was located in the Coulomb stress loading area of the 2008 earthquake (Fig. 6a). While, conversely, the epicenter of the 2020 earthquake was in the stress unloading area (Fig. 6b). Therefore, the coseismic and postseismic stress disturbance of the 2008 event was found to have potentially promoted the occurrence of the 2014 event, which is consistent with the results of previous studies (Bie et al. 2014b; Chen et al. 2014; Liu et al. 2015). Through our calculations and analysis, it was found that the coseismic stress disturbance increased from less than $0.01 \mathrm{MPa}$ to nearly $0.02 \mathrm{MPa}$ during the postseismic process, which indicates that the postseismic viscoelastic process cannot be ignored, especially in the Tibetan Plateau region, where the crustal stress can easily concentrate due to its low viscosity coefficient in the upper crust (Beaumont et al. 2001; Copley et al. 2011). 
Table 4

Layered rheological structure of the upper crust, lower crust and upper mantle.

\begin{tabular}{|llllll|}
\hline $\mathbf{m}$ & Depth $(\mathbf{k m})$ & $\begin{array}{l}\text { Vp } \\
(\mathbf{k m} / \mathbf{s})\end{array}$ & $\begin{array}{l}\text { Vs } \\
(\mathbf{k m} / \mathbf{s})\end{array}$ & $\begin{array}{l}\text { Density } \\
\left(\mathbf{k g} / \mathbf{m}^{3}\right)\end{array}$ & $\begin{array}{l}\text { Viscosity Coefficients } \\
(\mathrm{Pas})\end{array}$ \\
\hline 1 & $0 \sim 21$ & 6 & 3.5 & 2700 & 0 \\
\hline 2 & $21 \sim 43$ & 6.4 & 3.7 & 2850 & $1.0 \times 10^{18}$ \\
\hline 3 & $43 \sim 65$ & 7.1 & 3.9 & 3100 & $1.0 \times 10^{19}$ \\
\hline 4 & $>65$ & 8.2 & 4.6 & 3380 & $1.0 \times 10^{20}$ \\
\hline
\end{tabular}

Previous studies have shown that the change of calculation depths and viscosity coefficient can affects the stress relaxation time, but will not change the long-term trend of the variation in CFS (Ryder et al. 2012; Yu et al. 2020). As Fig. 6c shows, the rupture of the 2014 Yutian event resulted in the Coulomb stress decreasing slightly in the 2020 Yutian event. Taking the seismogenic fault of the 2020 earthquake as the receiving fault, the stress superposition effect of the two mainshocks of 2008 and 2014 was calculated, which showed that the stress disturbance in the epicenter region of the 2020 Yutian earthquake was generally decreased (Fig. 6d). Hence, we believe that the $2020 \mathrm{Mw} 6.4$ earthquake was not triggered by the 2008 and 2014 Yutian seismic events and that it is closely relate to the local regional tectonic background stress. The occurrence of the 2008 and 2014 Yutian earthquakes further accumulated the CFS changes on the eastern part of the Karakax fault and the southwest segment of the North Altyn fault, with the potential seismic risk of these fault zones further enhanced, where the future seismic risk should be paid close attention.

\subsection{Strain rate filed and tectonic implications}

The research from New Zealand and western North America indicates that short term seismicity can represent long term deformation with a reasonable accuracy (Walcott, 1984; Shen et al. 2007). Thus, the long-term tectonic setting can be characterized by regional seismicity in a certain period. Here, the Kostrov summation method (Kostrov 1974) was employed to calculate the strain rate tensors in the seismicity area of the interaction region of the Karakax, Gozha Co and southwestern Altyn Tagh faults in the northwestern Tibetan Plateau, as shown in Fig. 7. The historical earthquake catalog was derived from the GCMT, with a minimum moment magnitude of 4.3 , which is a global earthquake database compiled since 1976. The geodetic strain rate tensor along the principal axis was also calculated using the updated GNSS velocities (Yu et al. 2019). The patterns of principal strain axes revealed by seismic moment and geodetic observations were in good agreement, which both indicates that the strain accumulation of the fault system in this boundary area is mainly extensional, with a NW-SE trend. The principal extensional strain in the EW direction is obviously greater than the compression strain rate in the NS direction, which 
led to a large number of normal faulting earthquakes in the later direction. This also implies that the normal faulting between the West Kunlun and Bayan Har blocks exhibits a localized EW-trending extensional stress field. Noting that a series of normal slip and strike slip earthquake sequences in Yutian and the surrounding areas would have important implications on the current tectonic regime. Since the largest instrument recorded Yutian normal faulting earthquake (2008, Mw 7.1) in the northwest Tibetan Plateau, four major events have occurred in succession in the adjacent areas, including two mainshocks with an Mw of greater than 6.9 and two with $\mathrm{Mw}$ of $6.0 \sim 6.5$. These four earthquakes were located at the southwest end of North Altyn Tagh fault system, and were distributed along a NE-SW direction, with a gradual change from a normal dip slip in SW direction to a NE trending strike slip movement.

The Mw 6-7 earthquakes that occurred in the Yutian region in recent decade play an important role in understanding the deformation characteristics and the dynamic evolution process of the northern Tibetan Plateau. Given that the Coulomb stress accumulation from the 2008 and 2014 mainshocks was insufficient to trigger the 2020 earthquake, and contrarily, the epicenter region was located in the stress dropping area, so we hypothesize that this may have been determined by the regional long term tectonic environment. In fact, we found that almost all the seismic events in this triple junction area occurred at the boundary of the West Kunlun and Bayan Har blocks (Fig. 1). We interpret the occurrence of the 2020 Yutian earthquake as likely reflecting the release of the elastic strain accumulated mainly through localized tectonic movement rather than as a delayed triggering event caused by the previous Yutian earthquake sequences. It is considered that the accumulated elastic strain released by a series of normal faulting activities in the Tibetan Plateau could be closely related to the gravitational forces, which is obviously associated with topographic features (Elliott et al. 2010). The epicentral area of the 2020 Yutian earthquake is located in the gravitational spreading zone in consideration of the high elevation over $5000 \mathrm{~m}$ that contains high gravitational potential energy. Moreover, the majority of normal faulting earthquake sequences in a stepover zone are broadly distributed and closely linked to the strike slip faults especially in the southern Tibet, such as Damxung and Zhongba earthquake swarms. The slip rate discrepancy between the North Altyn Tagh fault and Longmu Co fault results in continuous extension in the local stepover zone. Hence, the occurrence of the Yutian earthquake sequences in recent decade was perhaps due to the structural response and strain adjustment of the left-lateral strike slip of the North Altyn Tagh fault. Through the Coulomb stress change calculations (Fig. 6d), we think that the NE-SW trending transitional zone in the triple junction between the North Altyn Tagh and Longmu Co fault systems will under a risk of moderate earthquake with Mw 6-7.

\section{Conclusions}

Constrained by the near-field ascending and descending Sentiel-1A/B radar images, we presented the InSAR coseismic deformation of the $2020 \mathrm{Mw} 6.4$ Yutian earthquake, which provided the opportunity to probe the seismic activity and tectonic context of the triple junction area in the northwestern Tibetan Plateau. We found that a major subsidence with a maximum LOS displacement of about $20 \mathrm{~cm}$ occurred near the western side of the epicentral zone. The optimal seismogenic fault parameters estimated by employing the Bayesian approach with an MCMC algorithm showed that this earthquake was dominated 
by a normal slip with a moderate strike slip component. Combined with the distribution of InSAR coseismic deformation field, aftershocks, focal mechanism solutions and regional tectonic background, we concluded that an NNE-SSW trending undefined normal faulting with a strike of $\sim 186^{\circ}$ and a dip of $\sim 60^{\circ}$ was responsible for this event, which exhibited a large normal-fault slip on a west-dipping plane with an almost nearly NS strike. The calculated coseismic slip in the uppermost crust was systematically smaller than that at the seismogenic depth, which may indicate a shallow fault slip, with a maximum slip of $\sim 1.0 \mathrm{~m}$ at a focal depth of $7 \mathrm{~km}$. The strain rate tensor estimated by the seismic moment and geodetic observations suggested that the Yutian earthquake sequences lies within a localized EW-trending extensional stepover zone. The 2020 Yutian seismic event was likely related to the local tectonic movement of the transition zone between the North Altyn Tagh fault and Longmu-Gozha Co fault rather than the coseismic and postseismic stress disturbance resulting from the 2008 and 2014 Yutian events.

\section{Abbreviations}

USGS: United States Geological Survey; GCMT: Global Centroid Moment Tensor; CENC: China Earthquake Networks Center; InSAR: Interferometric synthetic aperture radar; GNSS: Global Navigation Satellite System; LOS: line-of-sight; DEM: Digital Elevation Model; GACOS: Generic Atmospheric Correction Online Service; MCMC: Markov Chain Monte Carlo; PDFs: posterior probability density functions; CFS: Coulomb Failure Stress;

\section{Declarations}

\section{Acknowledgments}

The Sentinel-1A/B InSAR images used in this study were freely available and provided by Sentinels Scientific data Hub of Copernicus and European Space Agency. GNSS raw data were provided by the CMONOC Project (ftp.cgps.ac.cn), which were processed using the latest Bernese GNSS software. The PSGRN/PSCMP packages were provided by Prof. Wang Rongjiang at GeoForschungsZentrum Potsdam(GFZ). The figures are partly generated by the Generic Mapping Tools (GMT) software package (Wessel et al. 2013).

\section{Authors' contributions}

JY and BZ conceived and designed the experiments. JY drafted the original manuscript. BZ led the research work, proposed the crucial suggestions of this manuscript. DW and LQ contributed to some parts of the manuscript. All authors read and approved the final manuscript.

\section{Funding}

This research was supported by the Natural Science Foundation of Hubei Province (grant number 2019CFB794); the National Key Research and Development Program of China (grant number 2018YFC1503605) 
Availability of data and materials

The datasets used during the current study are available from the corresponding author on a reasonable request

\section{Ethics approval and consent to participate}

Not applicable.

\section{Competing interests}

The authors declare that they have no competing interests.

\section{Author details}

${ }^{1}$ Key Laboratory of Earthquake Geodesy, Institute of Seismology, CEA, Wuhan 430071, China. ${ }^{2}$ Institute of Disaster Prevention, Yanjiao, Sanhe City, Hebei Province, 065201, China.

\section{References}

1. Amey R, Hooper A, Walters R (2018) A Bayesian method for incorporating self-similarity into earthquake slip inversions. J Geophys Res Solid Earth 123:6052-6071. doi: 10.1029/2017JB015316

2. Armijo R, Tapponnier P, Mercier J, Han T (1986) Quaternary extension in southern Tibet: field observations and tectonic implications. J Geophys Res Solid Earth 91:13803-13872. doi: 10.1029/JB091iB14p13803

3. Bagnardi M, Hooper A (2018) Inversion of surface deformation data for rapid estimates of source parameters and uncertainties: a Bayesian approach. Geochem Geophys Geosyst 19:2194-2211. doi: 10.1029/2018GC007585

4. Beaumont C, Jamieson RA, Nguyen MH, Lee B (2001) Himalayan tectonics explained by extrusion of a low-viscosity crustal channel coupled to focused surface denudation. Nature 414(6865) 738-742. doi: $10.1038 / 414738 a$

5. Bassin C, Laske G, Masters G (2000) The Current Limits of Resolution for Surface Wave Tomography in North America. EOS Trans AGU81 F897.

6. Bie L, Ryder I, Nippress S, Bürgmann R (2014) Coseismic and post-seismic activity associated with the 2008 Mw 6.3 Damxung earthquake, Tibet, constrained by InSAR. Geophys J Int 196(2): 788-803. doi: $10.1093 / g j i / g g t 444$

7. Bie L, Ryder I (2014) Recent seismic and aseismic activity in the Ashikule stepover zone, NW Tibet. Geophys J Int 198(3): 1632-1643. doi: 10.1093/gji/ggu230

8. Chen C, Zebker H (2000) Network approaches to two-dimensional phase unwrapping: intractability and two new algorithms. J Opt Soc Am A 17:401-414. doi: 10.1364/JOSAA.17.000401 
9. Chen, H, Pan, Y, Dong, P, Zhang, H, Shi, Y (2014) Analysis of the stress environment of the 2008 and 2014 Yutian MS7.3 earthquakes. Chin J Geophys 57(10): 3238-3246 (in Chinese) doi:

$10.6038 /$ cjg20141012

10. Chen W, Qiao X, Xiong W, Yu P, Nie Z (2019) The 2007 Ning'er Mw 6.1 earthquake: A shallow rupture in Southwest China revealed by InSAR measurements. Earth Space Sci 6 doi:

10.1029/2019EA000555

11. Copley A, Avouac JP, Wernicke BP (2011) Evidence for mechanical coupling and strong Indian lower crust beneath southern Tibet. Nature 472(7341) 79-81. doi: 10.1038/nature09926

12. Elliott J, Walters RJ, England PC, Jackson JA, Li Z, Parsons B (2010) Extension on the Tibetan plateau: recent normal faulting measured by InSAR and body wave seismology. Geophys J Int 183(2) 503-535

13. Farr T, Rosen P, Caro E, Crippen R, Duren R, Hensley S, Kobrick M, Paller M, Rodriguez E, Roth L (2007) The shuttle radar topography mission. Rev Geophys 45(2). doi: 10.1029/2005RG000183

14. Fialko Y, Sandwell D, Simons M, et al (2005) Three-dimensional deformation caused by the Bam, Iran, earthquake and the origin of shallow slip deficit. Nature 435(7040): 295-9. doi:

$10.1038 /$ nature03425

15. Fukuda J, Johnson K (2010) Mixed linear-non-linear inversion of crustal deformation data: Bayesian inference of model, weighting and regularization parameters, Geophys J Int doi: 10.1111/j.1365246X.2010.04564.X

16. He P, Wen Y, Ding K, Xu C (2020) Normal faulting in the 2020 Mw 6.2 Yutian event: Implications for ongoing E-W thinning in northern Tibet. Remote Sens 12. doi: 10.3390/RS12183012

17. Jia K, Zhou S, Wang R (2012) Stress interactions within the strong earthquake sequence from 2001 to 2010 in the Bayankala block of eastern Tibet. Bull Seismol Soc Am 102(5) 2157-2164. doi: $10.1785 / 0120110333$

18. Jónsson S, Zebker H, Segall P, Amelung F (2002) Fault slip distribution of the 1999 M w 7.1 Hector mine, California, earthquake, estimated from satellite radar and GPS measurements. Bull Seismol Soc Am 92(4):1377-1389. doi: 10.1785/0120000922

19. Kaneko Y, Fialko Y (2011) Shallow slip deficit due to large strike-slip earthquakes in dynamic rupture simulations with elasto-plastic off-fault response. Geophys J Int 186(3), 1389-1403. doi: 10.1111/j.1365-246X.2011.05117.x

20. Kapp P, Taylor M, Stockli D, et al (2008) Development of active low-angle normal fault systems during orogenic collapse: Insight from Tibet. Geology 36(1):7-10. doi: 10.1029/2001TC001332

21. Kostrov BV (1974) Seismic moment and energy of earthquakes, and seismic flow of rock. Izv. Acad. Sci USSR Phys. Solid Earth Eng. Trans/ 1 23-44

22. Lewis T, Hyndman R, Flück P (2003) Heat flow, heat generation, and crustal temperatures in the northern Canadian Cordillera: thermal control of tectonics. J Geophys Res Solid Earth, 108(B6). doi: 10.1029/2002JB002090 
23. Li X, Xu W, Jónsson S, Klinger Y, Zhang G (2020) Source Model of the 2014 Mw 6.9 Yutian Earthquake at the Southwestern End of the Altyn Tagh Fault in Tibet Estimated from Satellite Images. Seismol Res Lett. doi: 10.1785/0220190361

24. Li Y, Chen L, Liu S, et al (2015) Coseismic Coulomb stress changes caused by the Mw6.9 Yutian earthquake in 2014 and its correlation to the 2008 Mw7.2 Yutian earthquake. J Asian Earth Sci 105:468-475. doi: 10.1016/j.jseaes.2015.02.025

25. Lin A, Jia D, Rao G, Yan B, Wu X, Ren Z (2011) Recurrent morphogenic earthquakes in the past millennium along the strike-slip Yushu fault, central Tibetan Plateau. Bull Seismol Soc Am 101(6):2755-2764. doi: 10.1785/0120100274

26. Liu, B, Shi, B, and Lei J. 2015. Effects of the 2008 and 2014 Yutian earthquake on seismic probabilities of adjacent faults. Chin J Geophys 58(2):463-473 (in Chinese) doi: $10.6038 /$ cjg20150210

27. Okada Y (1985) Surface deformation due to shear and tensile faults in a half-space. Bull Seismol SocAm 75(4):1135-1154.

28. Oglesby DD (2005) The dynamics of strike-slip step-overs with linking dip-slip faults. Bull Seismol Soc Am 95(5) 1604-1622. doi: 10.1785/0120050058

29. Ren J, Xu X, Yeats R, Zhang S. (2013) Millennial slip rates of the Tazang fault, the eastern termination of Kunlun fault: implications for strain partitioning in eastern Tibet. Tectonophysics 608 1180-1200. doi: 10.1016/j.tecto.2013.06.026

30. Ryder I, Bürgmann R, Sun J. (2010) Tandem afterslip on connected fault planes following the 2008 Nima-Gaize (Tibet) earthquake. J Geophys Res Solid Earth 115(B3) B03404. doi: 10.1029/2009JB006423

31. Ryder I, Bürgmann R, Pollitz F (2011) Lower crustal relaxation beneath the Tibetan Plateau and Qaidam Basin following the 2001 Kokoxili earthquake. Geophys J Int 187(2) 613-630. doi: 10.1111/j.1365-246X.2011.05179.x

32. Ryder I, Bürgmann R, Fielding E (2012) Static stress interactions in extensional earthquake sequences: An example from the South Lunggar Rift, Tibet. J Geophys Res Solid Earth 117(B9). doi: 10.1029/2012jb009365

33. Sandwell D, Mellors R, Tong XP, Wei M, Wessel P (2011) Open radar interferometry software for mapping surface deformation. Eos Trans AGU92(28). doi: 10.1029/2011E0280002.

34. Shen $Z$, Jackson D, Kagan $Y$ (2007) Implications of geodetic strain rate for future earthquakes, with a five-year forecast of M5 earthquakes in southern California. Seismol Res Lett 78(1):116-120. doi: 10.1785/gssrl.78.1.116

35. Shan X, Zhang G, Wang C et al (2011) Source characteristics of the Yutian earthquake in 2008 from inversion of the co-seismic deformation field mapped by InSAR. J Asian Earth Sci 40(4): 935-942. doi: 10.1016/j.jseaes.2010.05.011

36. Tapponnier P, Xu Z, Roger F, Meyer B, Arnaud N, Wittlinger G, Yang J (2001) Oblique stepwise rise and growth of the Tibet Plateau. science 294(5547): 1671-1677. doi: 10.1126/science.105978 
37. Taylor M, Yin A. (2009) Active structures of the Himalayan-Tibetan orogen and their relationships to earthquake distribution, contemporary strain field, and Cenozoic volcanism. Geosphere 5(3):199214. doi: $10.1130 /$ GES00217.1

38. Walcott R. (1984) The kinematics of the plate boundary zone through New Zealand: a comparison of short- and long-term deformations. Geophys J Int 79(2):613-633.

39. Wang, Q, Yang, W.B, Zhang, Z.F, Yang, Y.S, Wu, J.G, Dong, A.G, 2005. Geological characteristics of Neogene volcanic rocks in the Heishi North Lake area, Northwest Tibet, and their implications for the Neogene tectonic evolution. Geol Bull China 24 (1):80-86 (in Chinese)

40. Wang H, Elliott JR, Craig TJ, Wright TJ, Zeng JL, Hooper A (2014). Normal faulting sequence in the Pumqu-Xainza Rift constrained by InSAR and teleseismic body-wave seismology. Geochem Geophys Geosyst 15:2947-2. doi: 10.1002/2014GC005369

41. Wang H, Cao J, Hong S, Xu Y, Jing F (2016) Viscoelastic stress transfer between 2008 and 2014 Yutian M7 earthquakes, Xinjiang. Seismol and Geol 38 (3):646-655. doi: 10.3969/j.issn.02534967.2016.03.011

42. Wang R, Lorenzo-Martín F, Roth F (2006) PSGRN/PSCMP-A new code for calculating co-and postseismic deformation, geoid and gravity changes based on the viscoelastic-gravitational dislocation theory. Comput Geosci 32(4):527-541. doi: 10.1016/j.cageo.2005.08.006

43. Wessel P, Smith W. H F, Scharroo R, Luis J, Wobbe F (2013) Generic Mapping Tools: Improved Version Released. EOS Trans AGU 94(45):409-410. doi: 10.1002/2013eo450001

44. Wu C, Zhang Z, Zhao $C$ et al (2014) Yutian MS7.3 earthquake: Structural response of the Bayankala tectonic-block to eastward extrusion. Chin J Geophys 57(10): 3226-3237 (in Chinese) doi: 10.6038/cjg20141011

45. Xu X, Tan X, Yu G et al (2013) Normal- and oblique-slip of the 2008 Yutian earthquake: Evidence for eastward block motion, northern Tibetan Plateau. Tectonophysics 584:152-165. doi: 10.1016/j.tecto.2012.08.007

46. Xu C, Xu B, Wen Y, Liu Y (2016) Heterogeneous fault mechanisms of the 6 October 2008 MW 6.3 Dangxiong (Tibet) earthquake using interferometric synthetic aperture radar observations. Remote Sens 8(3):228. doi: 10.3390/rs8030228

47. Yu C, Li Z, Chen J et al (2018) Small Magnitude Co-Seismic Deformation of the 2017 Mw 6.4 Nyingchi Earthquake Revealed by InSAR Measurements with Atmospheric Correction. Remote Sens 10(5):684. doi: 10.3390/rs10050684

48. Yu J, Tan K, Zhang C, Zhao B, Wang D, Li Q (2019) Present-day crustal movement of the Chinese mainland based on Global Navigation Satellite System data from 1998 to 2018. Adv Space Res. doi: 10.1016/j.asr.2018.10.001

49. Yu J, Zhao B, Xu W, Wang D, Tan K (2020) Oblique fault movement during the 2016 Mw 5.9 Zaduo earthquake: insights into regional tectonics of the Qiangtang block, Tibetan Plateau. J Seismol 24:693-708. doi: 10.1007/s10950-020-09930-7 
50. Zhang G, Ma H, Wang H, Wang X (2005) Boundaries between active-tectonic blocks and strong earthquakes in the China mainland. Chinese J Geophys. 48(3):602-610 (in Chinese) doi: $10.1002 /$ cjg2.699

51. Zhang G, Qu C, Shan, X, Song X, Li Z, Hu J (2011) The coseismic InSAR measurements of 2008 Yutian earthquake and its inversion for source parameters. Chin J Geophys 54(11):2753-2760 (in Chinese) doi: 10.3969/j.issn.0001-5733.2011.11.005

52. Zhao B, Qi Y, Wang D, Yu J, Li Q, Zhang C (2018) Coseismic Slip Model of the 2018 M w 7.9 Gulf of Alaska Earthquake and Its Seismic Hazard Implications. Seismol Res Lett 90:642-648. doi: $10.1785 / 0220180141$

\section{Figures}

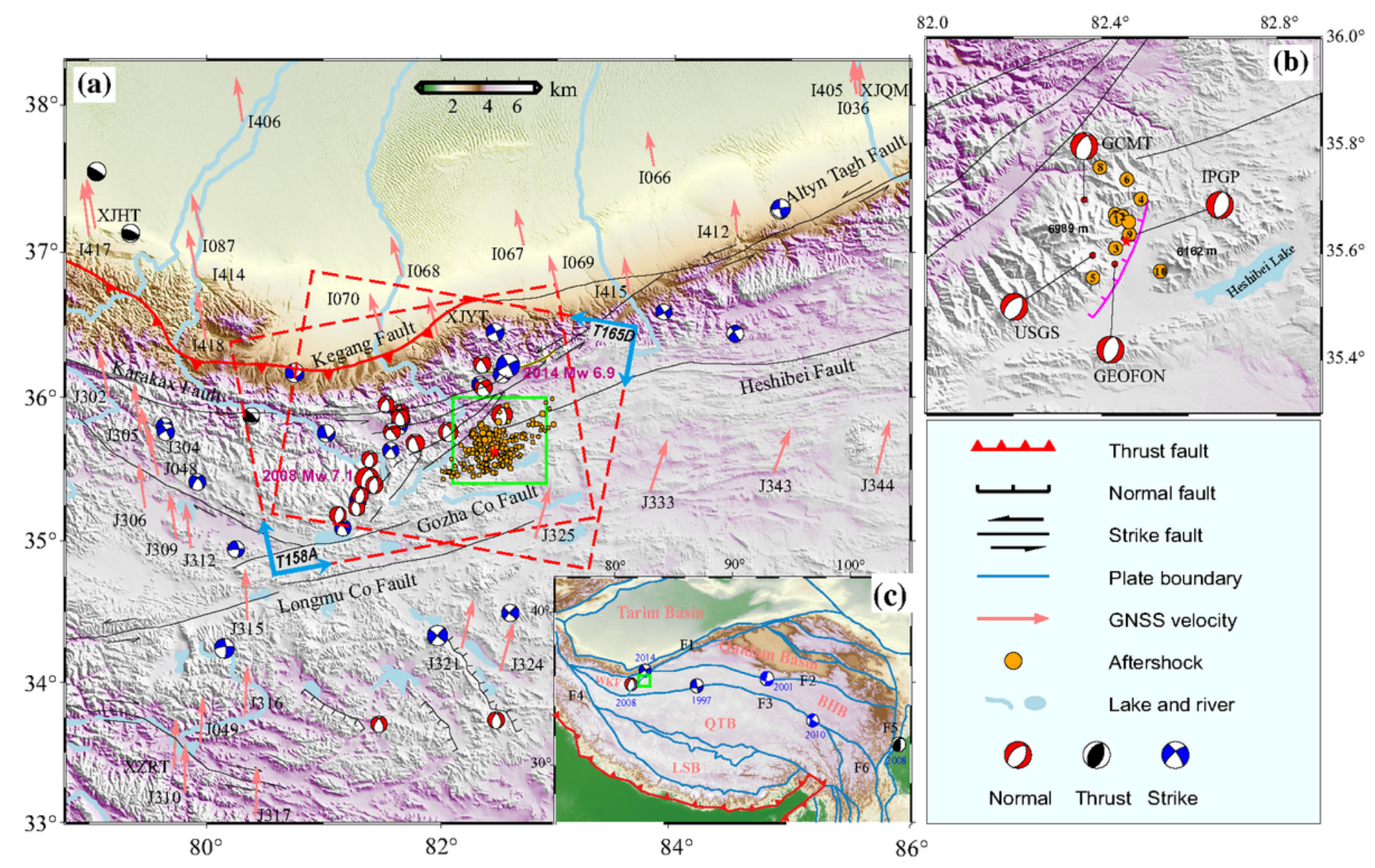

Figure 1

Topographic and tectonic settings of the $2020 \mathrm{Mw} 6.4$ Yutian earthquake. (a) The thin black lines denote the active faults located in the northwest Tibetan Plateau (Taylor and Yin, 2009). Beach balls in different color represent the focal mechanism solutions of normal faulting (red), thrust faulting (black) and strike faulting (blue) earthquake derived from the GCMT catalog. Light red arrows delineate GNSS velocities relative to the Eurasian reference frame (Yu et al. 2019). Red dashed rectangles outline the spatial 
coverage of the ascending and descending SAR images. The solid green box indicates the central area of the 2020 Yutian event. (b) Local tectonic environment in the epicentral area with four focal mechanism solutions from different institutions. The solid magenta line indicates the probably normal fault of this Yutian earthquake. The small orange circles denote the distribution of $\mathrm{M}>4$ aftershocks observed by the USGS until October 10,2020, and the numbers in the circle indicate the order of the occurrence. (c) The insert map shows the active blocks in the Tibetan Plateau and the distribution of destructive earthquakes surrounding the Bayan Har block. BHB = Bayan Har Block; Qiangtang Block = QTB; Lhasa Block = LSB; F1 = Altyn Tagh Fault; F2 = Kunlun Fault; F3 = Ganzi-Yushu Fault; F4 = Karakoram Fault; F5 = Longmenshan Fault; F6 = Xianshuihe Fault. Note: The designations employed and the presentation of the material on this map do not imply the expression of any opinion whatsoever on the part of Research Square concerning the legal status of any country, territory, city or area or of its authorities, or concerning the delimitation of its frontiers or boundaries. This map has been provided by the authors.
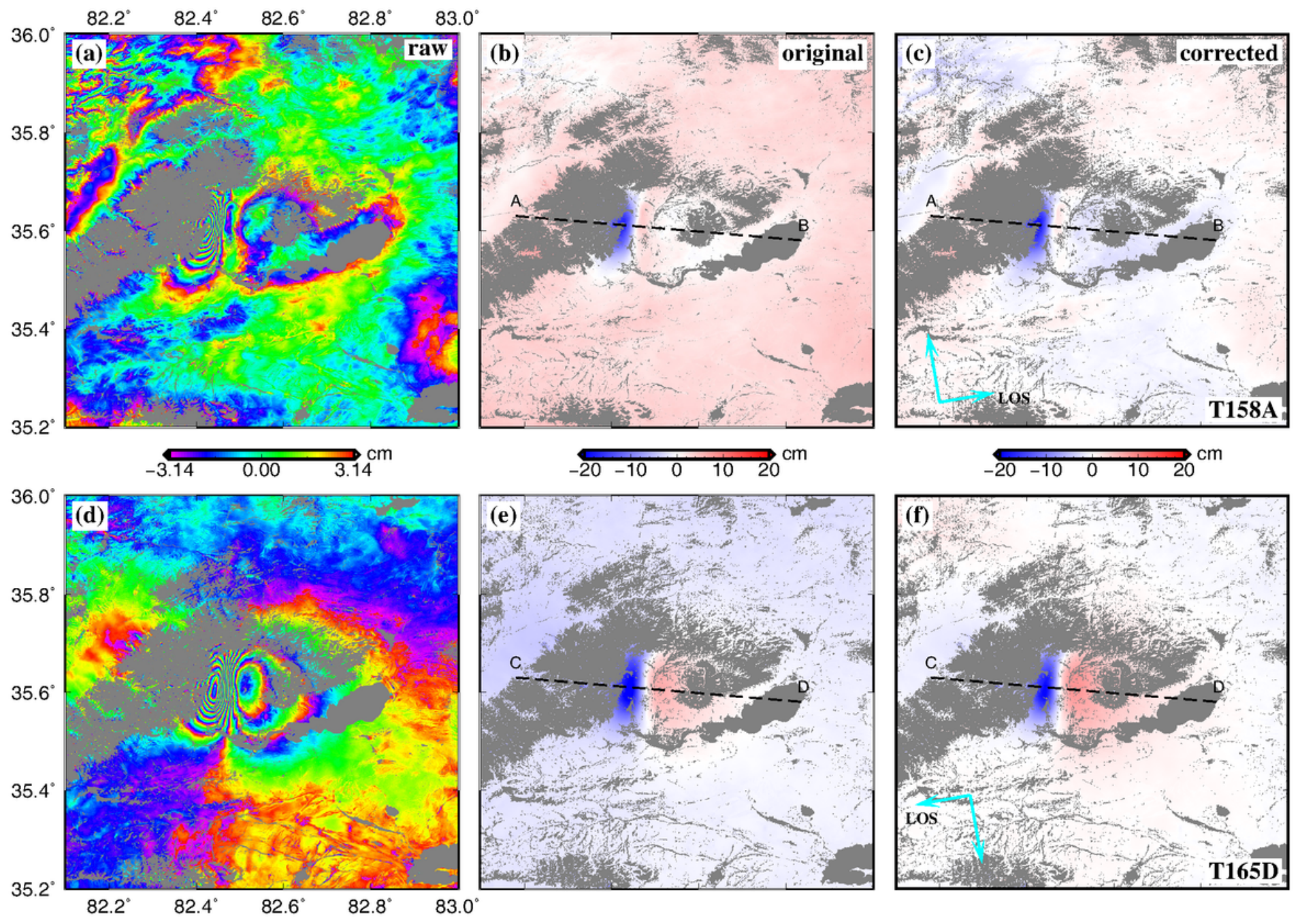

Figure 2

InSAR coseismic displacements of the 2020 Ms 6.4 Yutian earthquake. The wrapped phased interferograms (a, d), observed original (b, e) and GACOS corrected (c, f) InSAR coseismic deformation of the 2014 Yutian earthquake used in this study. Each fringe represents a displacement of $5.63 \mathrm{~cm}$ in the 
satellite LOS direction. The cyan arrows indicate the flight and look directions of the Sentinel-1 satellite. Note: The designations employed and the presentation of the material on this map do not imply the expression of any opinion whatsoever on the part of Research Square concerning the legal status of any country, territory, city or area or of its authorities, or concerning the delimitation of its frontiers or boundaries. This map has been provided by the authors.

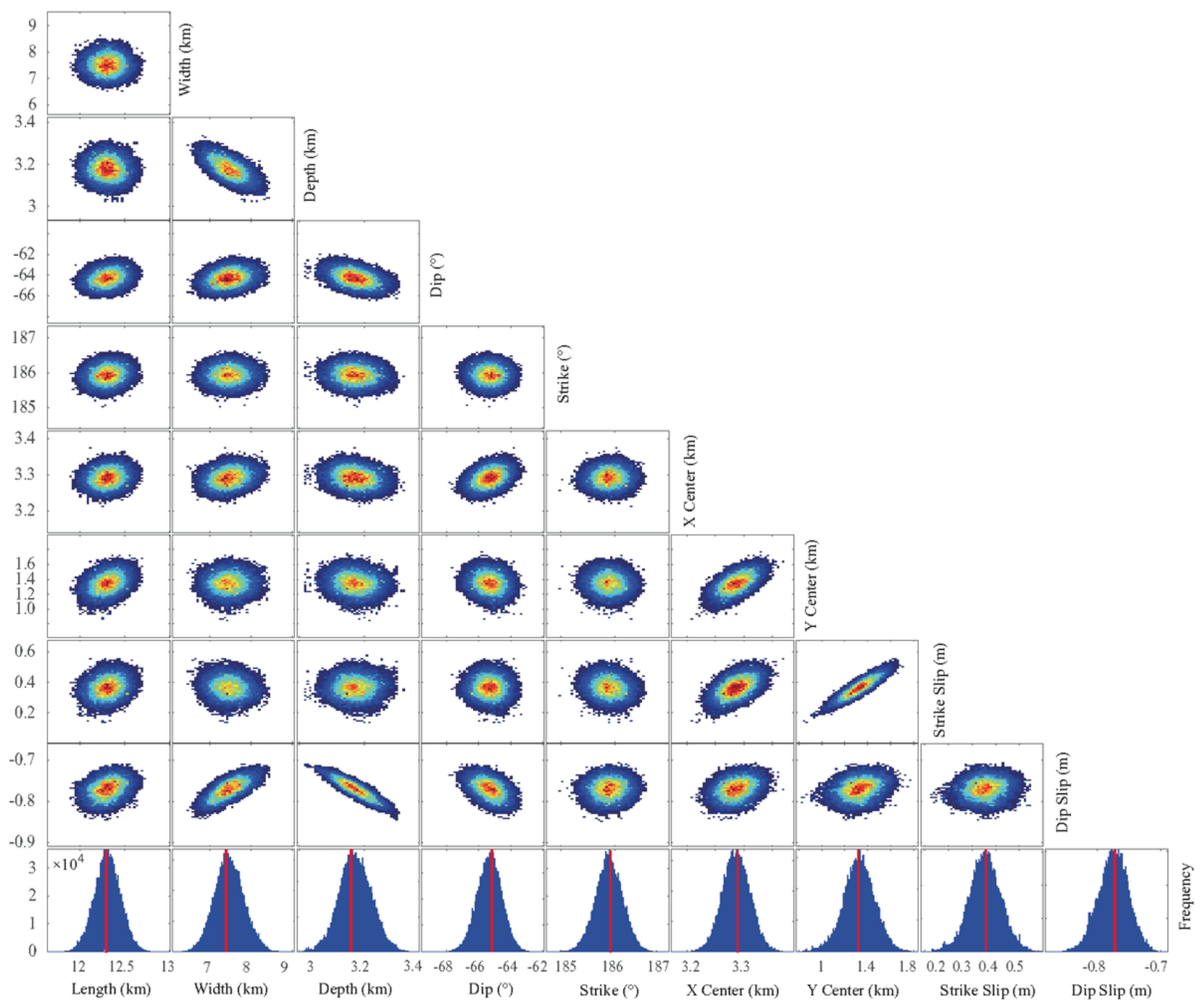

\section{Figure 3}

Marginal posterior probability distributions of the fault source parameters for the $2020 \mathrm{Mw} 6.4$ Yutian earthquake in the northwest Tibet. The scatter dots indicates occurrence frequency, with warm colors denoting high frequency and clod colors denoting low frequency. Bottom row: Histograms of model parameters; the best models are shown in thick red line with 95\% confidence interval bounds in red dashed lines. 

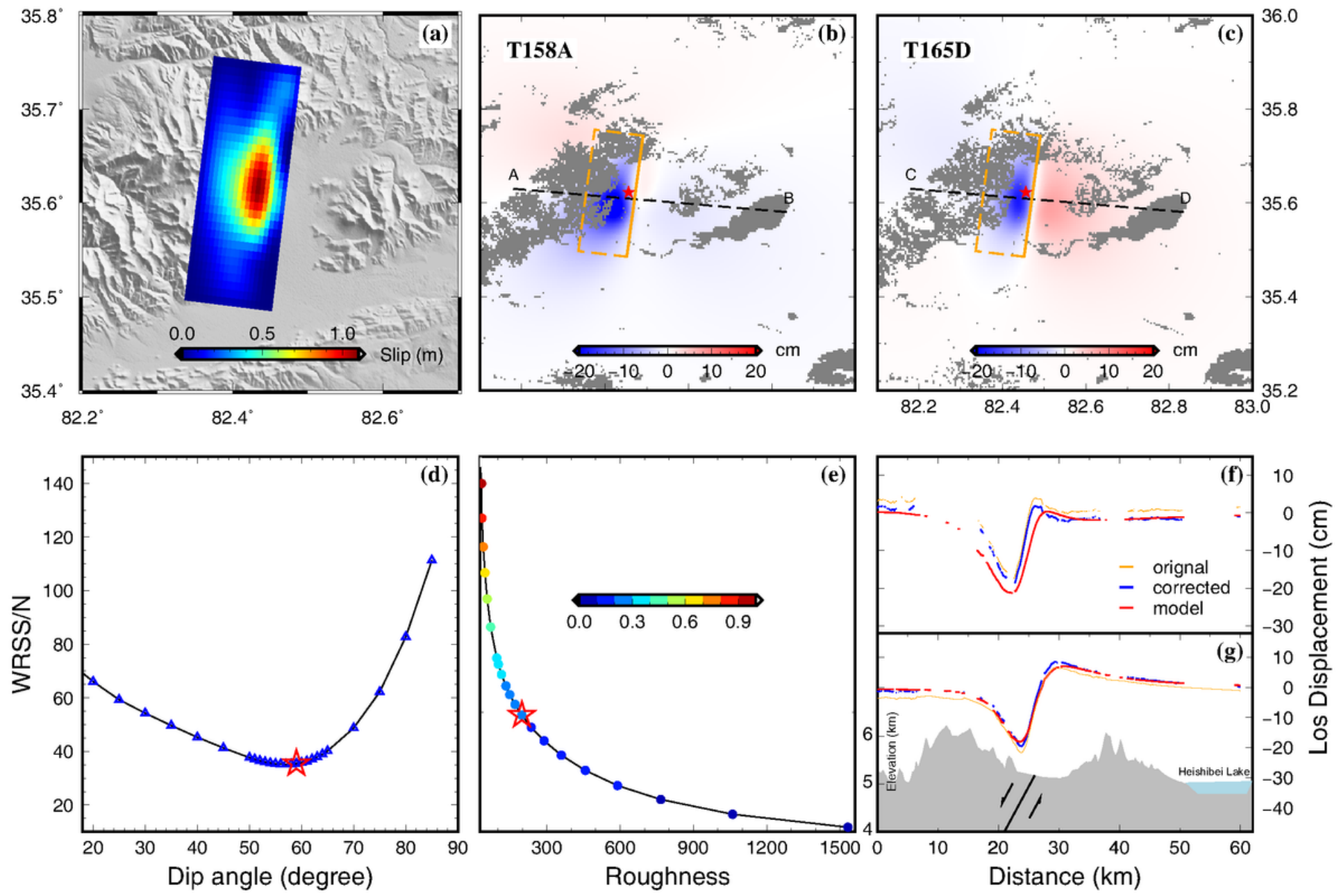

Figure 4

Inversion results using the optimal fault model. (a) The coseismic slip distribution of the $2020 \mathrm{Mw} 6.4$ Yutian earthquake. (b, c) Simulated coseismic deformation fields along the ascending (T158A) and descending (T165D) orbits. The orange rectangles outline the optimal fault plane projected onto the surface with the thicker line representing the down-dip edge of the fault plane. (d) Trade-off curve between the root-mean-square and fault dip. (e) Trade-off curve between the roughness and LOS data fitting residuals. ( $f, g$ ) Colored lines denote the original (orange), GACOS corrected (blue) and modeled (red) LOS displacements for profiles AB and CD across the fault, respectively. Gray shadow represents the topography profiles. 


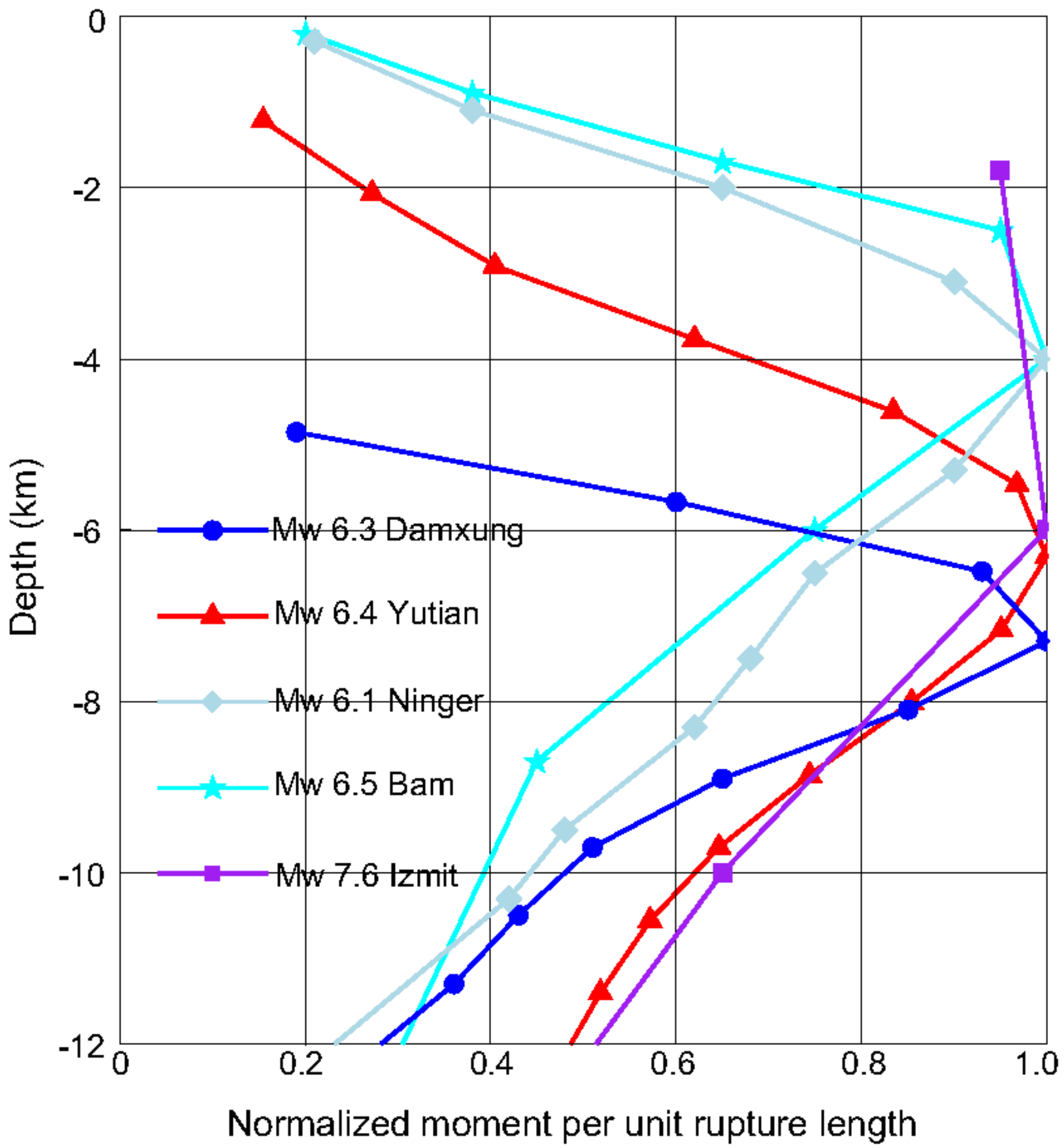

Figure 5

Distribution of seismic potency averaged along the fault length. All the seismic slip distributions were achieved from the near-filed geodetic observations. 


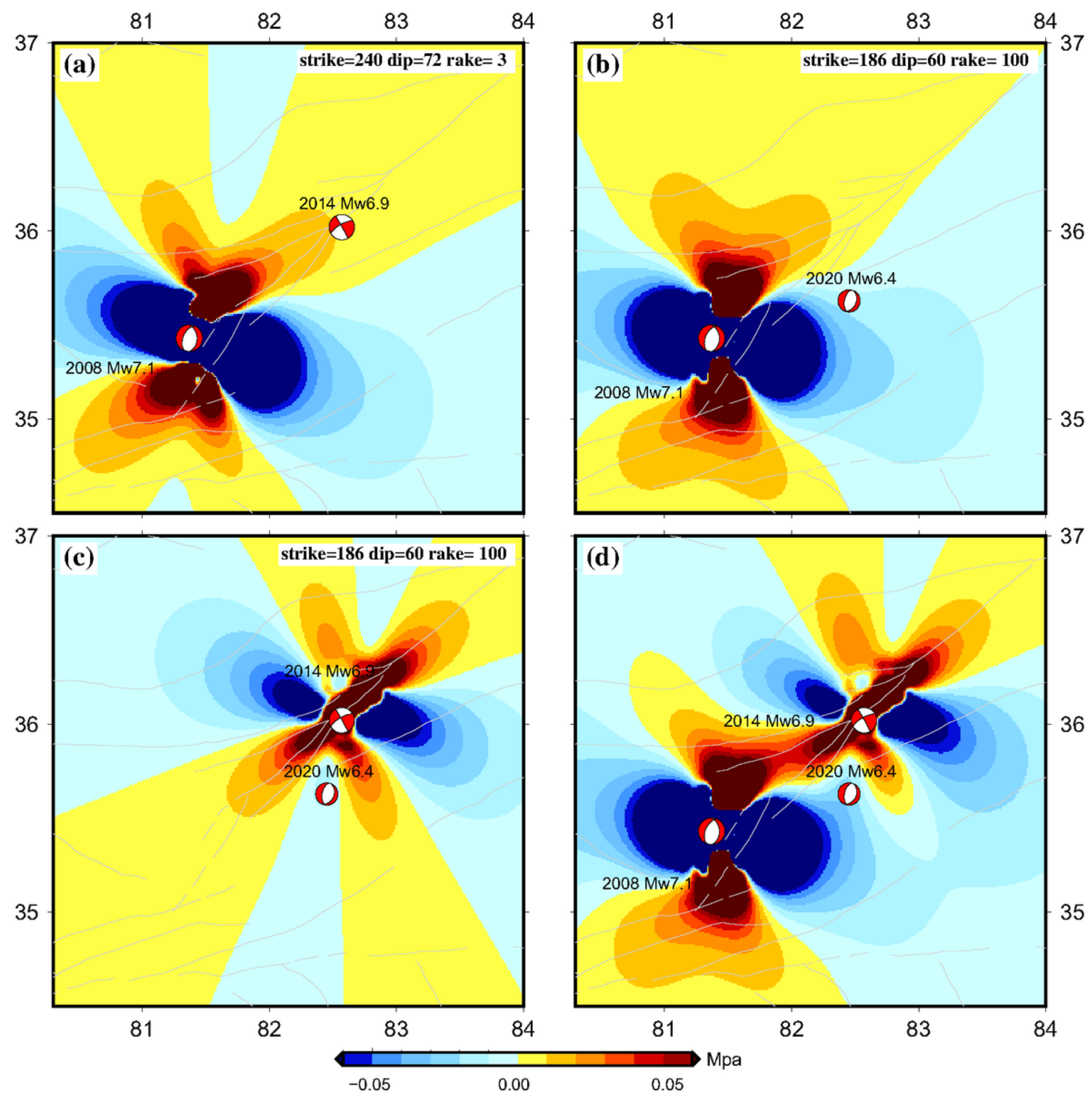

Figure 6

The projection of coseismic and postseismic Coulomb failure stress changes surrounding the Yutian earthquake sequences on the preferred rupture plane at a depth of $7 \mathrm{~km} .(a, b)$ The effects of coseismic and postseismic Coulomb stress changes induced by the 2008 mainshock for a receiver fault aligned with the $2014 \mathrm{Mw} 6.9$ and $2020 \mathrm{Mw} 6.4$ Yutian earthquakes, respectively. (c) The effects of coseismic and postseismic Coulomb stress changes brought about by the 2014 Mw 6.9 event on the 2020 Yutian 
earthquake. (d) The combined loading effects of the Coulomb failure stress changes at the hypocenter of the 2020 Yutian earthquake caused by the preceding two Mw $\otimes 6.9$ Yutian events.

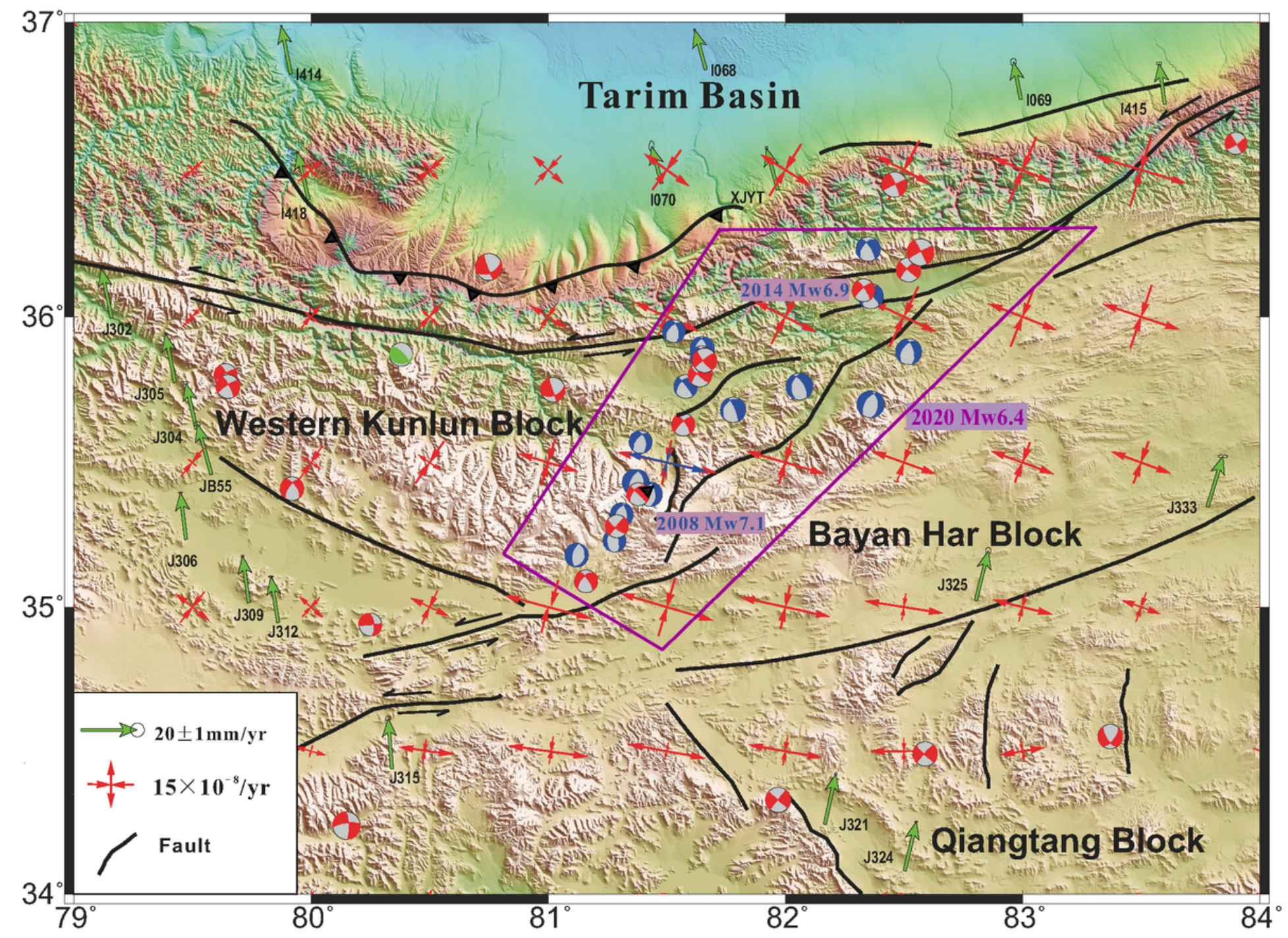

Figure 7

Summed-up focal mechanisms and principal-axes strain rate in the triple junction stepover region. Beach balls reflect the normal and strike faulting events. The red and blue vectors represent the principal strain rates calculated from the updated GNSS velocities and GCMT focal mechanisms, respectively.

\section{Supplementary Files}

This is a list of supplementary files associated with this preprint. Click to download.

- graphicalYu2.pdf 